\title{
Single-Reaction Multiplex Reverse Transcription PCR for Detection of Zika, Chikungunya, and Dengue Viruses
}

\author{
Jesse J. Waggoner, Lionel Gresh, \\ Alisha Mohamed-Hadley, Gabriela Ballesteros, \\ Maria Jose Vargas Davila, Yolanda Tellez, \\ Malaya K. Sahoo, Angel Balmaseda, \\ Eva Harris, Benjamin A. Pinsky
}

Clinical manifestations of Zika virus, chikungunya virus, and dengue virus infections can be similar. To improve virus detection, streamline molecular workflow, and decrease test costs, we developed and evaluated a multiplex real-time reverse transcription PCR for these viruses.

Z ika virus is a mosquitoborne flavivirus that, in 2015, spread throughout the tropical and subtropical regions of the Western Hemisphere. In January 2016, the first autochthonous cases of Zika fever were confirmed in Nicaragua (1). The diagnosis of human Zika virus infections is confounded by a nonspecific clinical presentation, which overlaps substantially with that of dengue virus (DENV) and chikungunya virus (CHIKV) $(2,3)$ and by cross-reaction with DENV IgM and DENV nonstructural protein 1 in assays for Zika virus (4-7).

Molecular assays can detect and differentiate these 3 pathogens during the acute phase of illness. Although a number of molecular tests have been published for detecting DENV and CHIKV, only 2 Zika virus real-time reverse transcription PCRs (rRT-PCRs) have been reported and were characterized by using human specimens $(6-8)$. These assays are run as individual reactions, and molecular testing for all 3 viruses, using established protocols, requires multiple reactions for a single patient sample $(6,9,10)$. We describe a Zika virus rRT-PCR that was designed to be run in multiplex with published assays for pan-DENV and CHIKV detection $(11,12)$. We then evaluated the singlereaction multiplex rRT-PCR for Zika virus, CHIKV, and

Author affiliations: Stanford University School of Medicine, Stanford, California, USA (J.J. Waggoner, A. Mohamed-Hadley, M.K. Sahoo, B.A. Pinsky); Sustainable Sciences Institute, Managua, Nicaragua (L. Gresh); Laboratory Centro Nacional de Diagnóstico y Referencia of the Ministry of Health, Managua (G. Ballesteros, M.J. Vargas Davila, Y. Tellez, A. Balmaseda); School of Public Health of the University of California, Berkeley, Berkeley, California, USA (E. Harris)

DOI: http://dx.doi.org/10.3201/eid2207.160326
DENV (referred to as the ZCD assay) by testing clinical samples from persons with suspected cases in Nicaragua.

\section{The Study}

The Zika virus primers and probe (online Technical Appendix Table 1 (http://wwwnc.cdc.gov/EID/article/22/7/160326-Techapp1.pdf) were designed by using all complete or nearly complete $(\geq 10,000 \mathrm{~kb})$ Zika virus genome sequences available in GenBank $(\mathrm{n}=21)$ accessed March $28,2014)$. Target sequences were subsequently confirmed to match strains from the Americas. All rRT-PCR reactions were performed on an ABI 7500 instrument (Applied Biosystems, Foster City, CA, USA) by using $25-\mathrm{mL}$ reactions of the SuperScript III Platinum One-Step qRT-PCR kit (Life Technologies, Carlsbad, CA, USA) and $5 \mathrm{~mL}$ of RNA template. Cycling conditions for the ZCD assay were as follows: $52^{\circ} \mathrm{C}$ for $15 \mathrm{~min} ; 94^{\circ} \mathrm{C}$ for $2 \mathrm{~min} ; 45$ cycles at $94^{\circ} \mathrm{C}$ for $15 \mathrm{sec}, 55^{\circ} \mathrm{C}$ for $20 \mathrm{sec}$ (acquisition), and $68^{\circ} \mathrm{C}$ for $20 \mathrm{sec}$. Each run included a no-template control and positive controls for Zika virus, CHIKV, and DENV.

Linear range and lower limit of $95 \%$ detection $(95 \%$ LLOD) for each target were determined as recommended. We determined linear range and 95\% LLOD for each target as recommended (13; online Technical Appendix). The linear range of the ZCD assay extended from $10^{8}$ to 10 copies $/ \mathrm{mL}$ for Zika virus and DENV-3 and from $10^{8}$ to 100 copies $/ \mathrm{mL}$ for DENV-1, $-2,-4$, and CHIKV. The 95\% LLOD for each target, in copies $/ \mathrm{mL}$ of eluate $(5 \mathrm{~mL}$ added to each $\mathrm{ZCD}$ reaction), was as follows: Zika virus, 7.8; CHIKV, 13.2; DENV1, 11.7; DENV-2, 13.5; DENV-3, 4.1; DENV-4, 10.5.

Assay exclusivity was established by testing genomic RNA from the following viruses: West Nile, Japanese encephalitis, tickborne encephalitis, yellow fever, Saint Louis encephalitis, o'nyong-nyong, Semliki Forest, Mayaro, Ross River, Getah, Barmah Fores, and Unas $(12,14)$. No amplification was detected for any of these viruses.

De-identified serum samples, collected from Nicaraguan patients with suspected Zika virus, CHIKV, and/or DENV infections, were tested (online Technical Appendix). We tested 216 samples by using the ZCD assay and the pan-DENV-CHIKV rRT-PCR, which is a validated duplex assay containing the DENV and CHIKV primers and probes used in the ZCD assay (12). Both assays were performed on an ABI7500 (Applied Biosystems) (Table 1). A total of 173 samples were positive for DENV alone 
Table 1. Comparison of DENV and CHIKV detection in the ZCD assay and pan-DENV-CHIKV rRT-PCR*

\begin{tabular}{lccccccc}
\hline & \multicolumn{4}{c}{ pan-DENV-CHIKV rRT-PCR } \\
\cline { 2 - 4 } \cline { 6 - 8 } ZCD assay & \multicolumn{3}{c}{ DENV Detection } & & \multicolumn{3}{c}{ CHIKV Detection } \\
\hline \multirow{3}{*}{ Pos } & Neg & Total & & Pos & Neg & Total \\
Nos & 55 & 5 & 60 & & 113 & 23 & 136 \\
Neg & 3 & 153 & 156 & & 12 & 68 & 80 \\
Total & 58 & 158 & 216 & & 125 & 91 & 216 \\
\hline
\end{tabular}

${ }^{*} \mathrm{CHIKV}$, chikungunya virus; DENV, dengue virus; neg, negative; pos, positive; rRT-PCR, real-time reverse transcription PCR; ZCD assay, single-reaction multiplex rRT-PCR for Zika virus, CHIKV, and DENV

$(\mathrm{n}=25)$, CHIKV alone $(\mathrm{n}=110)$, or both $(\mathrm{n}=38)$. The ZCD assay and pan-DENV-CHIKV rRT-PCR showed very good agreement for DENV detection $(\mathrm{k}=0.907)$. Six of 8 discrepant samples were co-infected with DENV and CHIKV, and the 2 discrepant samples with DENV mono-infections had cycle threshold $\left(\mathrm{C}_{\mathrm{t}}\right)$ values of 41.34 and 42.25. The 2 assays demonstrated good agreement for CHIKV detection $(\mathrm{k}=0.662) . \mathrm{C}_{\mathrm{t}}$ for the $35 \mathrm{CHIKV}$ discrepant samples were reached significantly later (mean $39.8, \mathrm{SD} \pm 1.5)$ than the 113 concordant samples $(28.7$, \pm SD 9.7; $<<0.0001$ ).

The first case of Zika virus infection in Nicaragua was detected with the ZCD assay during the assay comparison described above. After Zika virus identification, 133 consecutive samples were tested by using both the ZCD assay and a comparator Zika virus rRT-PCR targeting the capsid gene (6) (Table 2). When the comparator rRT-PCR was analyzed according to the published validation $\left(\mathrm{C}_{\mathrm{t}} \leq 38.5\right.$ defining a positive result), these assays demonstrated only moderate agreement $(\mathrm{k}=0.47)$, and Zika virus was detected in significantly more samples by using the ZCD assay $(p<0.001)$. Of the 31 samples positive only for Zika virus in the ZCD assay, $22(71 \%)$ produced a $\mathrm{C}_{\mathrm{t}}(>38.5)$ that was reached later in the comparator Zika virus rRT-PCR. These 22 samples had mean $\mathrm{C}_{\mathrm{t}}$ of $32.06(\mathrm{SD} \pm 2.45)$ in the $\mathrm{ZCD}$ assay and 42.09 ( $\mathrm{SD} \pm 1.41)$ in the comparator Zika virus rRT-PCR. If all samples in the comparator rRT-PCR with $\mathrm{C}_{\mathrm{t}}>38.5$ were considered positive, the assays demonstrated very good agreement $(\mathrm{k}=0.81$; online Technical Appendix Table 2). Of the 56 Zika virus-positive samples in the ZCD assay, 39 were positive only for Zika virus, and 17

Table 2. Comparison of Zika virus detection in the ZCD assay and the Zika virus comparator rRT-PCR*

\begin{tabular}{lccc} 
& \multicolumn{3}{c}{ Zika virus rRT-PCR } \\
\cline { 2 - 4 } ZCD assay & Pos & Neg & Total \\
\hline Pos & 25 & $31 \dagger$ & 56 \\
Neg & $1 \ddagger$ & 76 & 77 \\
Total & 26 & 107 & 133 \\
\hline
\end{tabular}

${ }^{*} \mathrm{CHIKV}$, chikungunya virus; $\mathrm{C}_{\mathrm{t}}$, cycle threshold; DENV, dengue virus; neg, negative; pos, positive; rRT-PCR, real-time reverse transcription PCR; ZCD assay, single-reaction multiplex rRT-PCR for Zika virus, CHIKV, and DENV.

$\dagger 22$ samples produced a late $\mathrm{C}_{t}$ in the comparator Zika virus rRT-PCR ( $\mathrm{C}_{t}$ $>38.5$ )

$\ddagger$ Sample was also pos for a DENV-CHIKV co-infection and tested pos for Zika virus when repeated in the ZCD assay. showed evidence of mixed infection: Zika virus-DENV ( $=3$ ); Zika virus-CHIKV $(\mathrm{n}=10)$, or Zika virus-CHIKV$\operatorname{DENV}(\mathrm{n}=4)$.

\section{Conclusions}

The ZCD assay improved detection of Zika virus relative to the comparator rRT-PCR, and 31 samples were positive only for Zika virus by the ZCD assay when the comparator was interpreted as published (6). Notably, 22 (71\%) of these 31 samples produced a late signal in the comparator Zika virus rRT-PCR $\left(\mathrm{C}_{\mathrm{t}}>38.5\right)$, indicating that these most likely are true, late-positive results. Improved sensitivity for Zika virus is needed given the low viremia detected in clinical samples and the current lack of accurate alternative diagnostics, such as serology $(6,7,15)$. Additionally, the ZCD assay identified 17 co-infections in Zika viruspositive patients. Although preliminary, these data provide evidence for the utility of a multiplex diagnostic test for these pathogens.

The performance of the ZCD assay for DENV detection was similar to that of the pan-DENV-CHIKV rRTPCR, and the analytical sensitivity for CHIKV was similar in both assays (12). CHIKV detection in clinical samples in the ZCD assay and pan-DENV-CHIKV rRT-PCR demonstrated good agreement, although both assays contain the same CHIKV primers and probes. Discrepant samples all had $\mathrm{C}_{\mathrm{t}}$ of $\geq 37.36$, which correspond to $10 \mathrm{copies} / \mathrm{mL}$ of eluate and fall below the 95\% LLOD. Although ZCD assay results for these CHIKV-positive samples were reproducible, the clinical significance of such low-level viremia in patients with suspected chikungunya fever is unclear and warrants further study.

A limitation to our study is the use of a single comparator Zika virus rRT-PCR. This assay was 1 of 2 rRT-PCRs developed for the 2007 Yap Island Zika virus strain (6). The second rRT-PCR, targeting the membrane gene, was evaluated for the current study but proved consistently less analytically sensitive. Therefore, performance of this second Zika virus assay most likely would not have affected result interpretation.

In conclusion, the single-reaction multiplex ZCD assay detected and differentiated Zika virus, CHIKV, and DENV. This assay should streamline molecular workflow and decrease test costs while improving detection of these 3 human arboviruses.

\section{Acknowledgments}

We thank Lark L. Coffey for providing genomic RNA from reference alphavirus isolates. We thank the staff of the Stanford Clinical Virology Laboratory, and we are grateful to past and present members of the study team based at the Centro de Salud Sócrates Flores Vivas, the National Virology Laboratory in the Centro Nacional de Diagnóstico y Referencia of the Nicaraguan 
Ministry of Health, and the Sustainable Sciences Institute in Managua, Nicaragua.

Patent applications or provisional patent applications that cover the ZCD multiplex assay and the primers and probes described in this report have been filed (J.J.W. and B.A.P.).

This research was supported by National Institute of Allergy and Infectious Diseases of the National Institutes of Health (NIH) grant K08AI110528 (to J.J.W.) and the Robert E. Shope International Fellowship in Infectious Diseases from the American Society of Tropical Medicine and Hygiene. Studies in Nicaragua were supported by NIH grants R01AI099631 (to A.B.) and U54AI65359 (to A.B.), NIH contract HHSN2722001000026C (to E.H. and A.B.), and VE-1 (to E.H.) from the Pediatric Dengue Vaccine Initiative. The funders had no role in study design, data collection and analysis, decision to publish, or preparation of the manuscript.

Dr. Waggoner is an instructor in the Division of Infectious Diseases and Geographic Medicine at the Stanford University School of Medicine, Stanford, California. His research intrests include implementation and evaluation of improved diagnostics for pathogens important to the global health community

\section{References}

1. El Nuevo Diario. Confirman dos casos positivos de Zika en Nicaragua [cited 2016 Apr 13]. http://www.elnuevodiario.com.ni/ nacionales/383401-nicaragua-confirma-dos-casos-positivos-zika/

2. Duffy MR, Chen TH, Hancock WT, Powers AM, Kool JL, Lanciotti RS, et al. Zika virus outbreak on Yap Island, Federated States of Micronesia. N Engl J Med. 2009;360:2536-43. http://dx.doi.org/10.1056/NEJMoa0805715

3. Zanluca C, Melo VC, Mosimann AL, Santos GI, Santos CN, Luz K. First report of autochthonous transmission of Zika virus in Brazil. Mem Inst Oswaldo Cruz. 2015;110:569-72. http://dx.doi.org/10.1590/0074-02760150192

4. Fonseca K, Meatherall B, Zarra D, Drebot M, MacDonald J, Pabbaraju K, et al. First case of Zika virus infection in a returning Canadian traveler. Am J Trop Med Hyg. 2014;91:1035-8. http://dx.doi.org/10.4269/ajtmh.14-0151

5. Gyurech D, Schilling J, Schmidt-Chanasit J, Cassinotti P, Kaeppeli F, Dobec M. False positive dengue NS1 antigen test in a traveller with an acute Zika virus infection imported into Switzerland. Swiss Med Wkly. 2016;146:w14296.

6. Lanciotti RS, Kosoy OL, Laven JJ, Velez JO, Lambert AJ, Johnson AJ, et al. Genetic and serologic properties of Zika virus associated with an epidemic, Yap State, Micronesia, 2007. Emerg Infect Dis. 2008;14:1232-9. http://dx.doi.org/10.3201/ eid1408.080287

7. Waggoner JJ, Pinsky BA. Zika virus: diagnostics for an emerging pandemic threat. J Clin Microbiol. 2016;54:860 7.;54:860-7. http://dx.doi.org/10.1128/JCM.00279-16

8. Faye O, Faye O, Dupressoir A, Weidmann M, Ndiaye M, Alpha Sall A. One-step RT-PCR for detection of Zika virus. J Clin Virol. 2008;43:96-101. http://dx.doi.org/10.1016/ j.jcv.2008.05.005

9. Lanciotti RS, Kosoy OL, Laven JJ, Panella AJ, Velez JO, Lambert AJ, et al. Chikungunya virus in US travelers returning from India, 2006. Emerg Infect Dis. 2007;13:764-7. http://dx.doi.org/10.3201/eid1305.070015

10. Lanciotti RS, Calisher CH, Gubler DJ, Chang GJ, Vorndam AV. Rapid detection and typing of dengue viruses from clinical samples by using reverse transcriptase-polymerase chain reaction. J Clin Microbiol. 1992;30:545-51.

11. Waggoner JJ, Abeynayake J, Sahoo MK, Gresh L, Tellez Y, Gonzalez K, et al. Development of an internally controlled real-time reverse transcriptase PCR assay for pan-dengue virus detection and comparison of four molecular dengue virus detection assays. J Clin Microbiol. 2013;51:2172-81. http://dx.doi.org/10.1128/JCM.00548-13

12. Waggoner JJ, Ballesteros G, Gresh L, Mohamed-Hadley A, Tellez Y, Sahoo MK, et al. Clinical evaluation of a single-reaction real-time RT-PCR for pan-dengue and chikungunya virus detection. J Clin Virol. 2016;78:57-61. http://dx.doi.org/10.1016/ j.jcv.2016.01.007

13. Burd EM. Validation of laboratory-developed molecular assays for infectious diseases. Clin Microbiol Rev. 2010;23:550-76. http://dx.doi.org/10.1128/CMR.00074-09

14. Waggoner JJ, Abeynayake J, Sahoo MK, Gresh L, Tellez Y, Gonzalez K, et al. Single-reaction, multiplex, real-time RT-PCR for the detection, quantitation, and serotyping of dengue viruses. PLoS Negl Trop Dis. 2013;7:e2116. http://dx.doi.org/10.1371/ journal.pntd.0002116

15. Musso D, Roche C, Nhan TX, Robin E, Teissier A, Cao-Lormeau VM. Detection of Zika virus in saliva. J Clin Virol. 2015;68:53-5. http://dx.doi.org/10.1016/j.jcv.2015.04.021

Address for correspondence: Benjamin A. Pinsky, 3375 Hillview Ave, Room 2913, Palo Alto, CA 94304, USA; email: bpinsky@stanford.edu

\section{Letters}

Letters commenting on recent articles as well as letters reporting cases, outbreaks, or original research are welcome. Letters commenting on articles should contain no more than 300 words and 5 references; they are more likely to be published if submitted within 4 weeks of the original article's publication. Letters reporting cases, outbreaks, or original research should contain no more than 800 words and 10 references. They may have 1 Figure or Table and should not be divided into sections. All letters should contain material not previously published and include a word count.

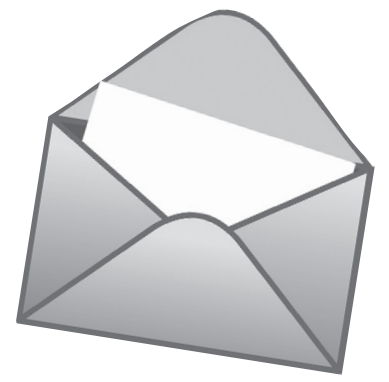

